\title{
Sociodemographic and clinical profile of patients treated with oral anticoagulants
}

\author{
Perfil sociodemográfico e clínico de pacientes em tratamento com anticoagulantes orais
}

Thaisa Remigio Figueirêdo ${ }^{1}$, Hirla Vanessa Soares de Araújo ${ }^{1}$, Tâmara Silva ${ }^{1}$, Maria Mariana Barros Melo da Silveira $^{1}$, Christefany Régia Braz Costa ${ }^{2}$, Simone Maria Muniz da Silva Bezerra ${ }^{1}$

Objective: to describe the sociodemographic and clinical profile of patients treated with oral anticoagulants. Methods: cross-sectional study, conducted in an anticoagulation outpatient facility of a teaching hospital which is reference in cardiology. One evaluated 222 patients, through individual interviews using a structured questionnaire. Data were analyzed using descriptive statistics. Results: the participants were characterized predominantly by the following characteristics: female (64.4\%); brown (57.2\%); low education (68.0\%); poor (67.1\%); most with values of the International Normalized Ratio outside the therapeutic range (57.2\%); associated comorbidities and prolonged treatment time (65.8\%). Conclusion: it was evident a predominantly female group, with low socioeconomic status, associated comorbidities and prolonged treatment time with oral anticoagulants. It constitutes the biggest part of a vulnerable group whose characteristics can affect the quality of the treatment, and with characteristics related to the particular culture of northeastern Brazil, not found in anticoagulation outpatient facilities in other regions of the country.

Descriptors: Cardiovascular Diseases; Anticoagulants; Health Profile.

Objetivo: descrever o perfil sociodemográfico e clínico de pacientes em tratamento com anticoagulantes orais. Métodos: estudo transversal, desenvolvido em ambulatório de anticoagulação de um hospital de ensino e referência na área de Cardiologia. Foram avaliados 222 pacientes, por meio de entrevistas individuais, com questionário estruturado. Os dados foram analisados usando estatística descritiva. Resultados: os participantes caracterizaram-se predominantemente por: sexo feminino $(64,4 \%)$; cor parda $(57,2 \%)$; baixa escolaridade (68,0\%); baixa renda (67,1\%); maioria apresentando valores do International Normalized Ratio fora da faixa terapêutica (57,2\%); comorbidades associadas; e tempo de tratamento prolongado $(65,8 \%)$. Conclusão: evidenciou-se grupo predominantemente do sexo feminino, com baixo nível socioeconômico, comorbidades associadas e tempo de tratamento prolongado com anticoagulantes orais. Constitui-se, em maior parte, de um grupo vulnerável, cuja característica pode interferir na qualidade do tratamento, e com especificidades relacionadas à cultura particular da região Nordeste do Brasil, não encontradas em ambulatórios de anticoagulação de outras regiões do país.

Descritores: Doenças Cardiovasculares; Anticoagulantes; Perfil de Saúde.

\footnotetext{
${ }^{1}$ Universidade de Pernambuco. Recife, PE, Brazil.

${ }^{2}$ Universidade de São Paulo. Ribeirão Preto, SP, Brazil. 


\section{Introduction}

The document "Better Population Through Behavior Change in Adults: A Call to Action", published by the American Heart Association, presents cardiovascular diseases as epidemic and with potential impact in terms of populational health ${ }^{(1)}$. Estimates from the World Health Organization indicate cardiovascular diseases as the leading cause of death and disability worldwide, with an upward trend and negative projection for 2030, resulting in noticeable fall in overall productivity ${ }^{(2)}$.

Oral anticoagulants are characterized by frequent indication for some of these diseases, with safety and efficacy proven in the management and prevention of thromboembolic events, arising from various heart diseases and bleeding disorders ${ }^{(3)}$.

Chronic anticoagulation therapy is considered, however, a dilemma, because once it reduces thromboembolic events, it also provides an increased risk of bleeding. In addition, the instability of this treatment has been considered a problem since the discovery of these drugs ${ }^{(4)}$.

There are some factors that influence blood clotting and that can lead the patient to increased risk of bleeding or thromboembolism, it is pointed out that these are related to individual aspects, food and drug interactions ${ }^{(5)}$.

The use of oral anticoagulants requires care by patients. To enjoy the protective benefits of oral anticoagulation and make sure the treatment is safe, it is essential the strict control of blood clotting rates ${ }^{(4)}$. It is estimated that annual risks associated with the use of oral anticoagulants are between 2 and $8.0 \%$ for bleeding and 1 to $3.0 \%$ related to treatment failure, and one of the means to prevent complications related to the treatment is frequent laboratory monitoring ${ }^{(6)}$.

For monitoring blood coagulation, laboratory tests are used, such as Partial Thromboplastin Time and Prothrombin Time, expressed by the International Normalized Ratio. The determination of this substantially improved the quality of monitoring of anticoagulated patients, allowing to identify the maintenance of values within the therapeutic range $\mathrm{e}^{(4)}$.

Therefore, one recognizes the importance of identifying the profile of patients with precise indications of oral anticoagulation due to the variation in the population characteristics of these individuals. One also added that the production of knowledge on the subject in the Northeast of Brazil is incipient. Thus, the study describes the sociodemographic and clinical profile of patients treated with oral anticoagulants.

\section{Methods}

Cross-sectional study, carried out in the anticoagulation clinic of a university cardiac emergency unit of Pernambuco, reference in cardiology for the North and Northeast regions of Brazil, from March to June 2015. The hospital organizes patient care using oral anticoagulants on an outpatient basis. Schedules of patients are carried out in accordance with the need to control the levels of the International Normalized Ratio.

The target population corresponded to patients using oral anticoagulant and accompanied in an outpatient unit. The present study included patients who met the inclusion criteria: age equal to or above 18 years old, being treated with warfarin, presenting minimum capacity of understanding regarding the application of data collection instruments. Those patients unable to communicate orally with the interviewer were excluded.

The sample was the type probabilistic, obtained in a simple random way, through a raffle based on the number from the order list of patients to be treated in the consultation days, totaling at the end of the study, 222 patients.

Each patient, at the welcoming moment, was given a card with a number that could range from 1 to 100 , through which raffles would be performed. Data collection was conducted through individual inter- 
views with the patient during outpatient care.

Data were stored and analyzed using descriptive and inferential statistics tools, using software Statistical Package for Social Sciences (version 20.0). One conducted descriptive analyzes of single frequency for nominal variables, and mean and standard deviation for continuous. For comparison of the percentages found in the frequency analysis, one used the Chi-square test for proportions comparison, in the absence of outcome.

The study complied with the formal requirements contained in the national and international regulatory standards for research involving human beings.

\section{Results}

Regarding socio-demographic data (Table 1), it was possible to observe that, in a significant way, there was a predominance of female subjects (64.4\%); age ranged from 18 to 87 years old, averaging $54.7 \pm 3.8$, and $63.5 \%$ were younger than 60 years old; $57.2 \%$ declared themselves browns; $54.5 \%$ were married/ civil union; and $72.5 \%$ were from the metropolitan area of Recife, Pernambuco, Brazil. It was also found that $68.0 \%$ of the respondents had up to nine years of study, out of these, $43.7 \%$ had incomplete elementary education and $14.0 \%$ were not educated at all; $57.2 \%$ were retired/pensioners; and $67.1 \%$ reported family income of up to one minimum wage.

When considering the most frequent clinical aspects, $91.0 \%$ had hypertension, $53.6 \%$ were sedentary, $38.7 \%$ reported stress and $38.3 \%$ dyslipidemia (Table 2). As for medicines used by patients, 91.0\% were using antihypertensive drugs, $22.9 \%$ used statins, $22.1 \%$ antiarrhythmic drugs, $10.8 \%$ hypoglycemic and $9.4 \%$ digitalis. Approximately $15.3 \%$ of the patients were on antibiotics at the time of the interview.
Table 1 - Socio-demographic and economic characterization of patients using oral anticoagulants $(n=222)$

\begin{tabular}{lc}
\hline Variables & $\mathbf{n}(\%)$ \\
\hline Gender & $79(35.6)$ \\
Male & $143(64.4)$ \\
Female & \\
Age (years) & $141(63.5)$ \\
$<60$ & $81(36.5)$ \\
$\geq 60$ & \\
Ethnicity & $70(31.5)$ \\
White & $127(57.2)$ \\
Brown & $24(10.8)$ \\
Black & $1(0.5)$ \\
Indigenous & \\
Marital status & $121(54.5)$ \\
Married / stable Union & $18(8.1)$ \\
Divorced & $27(12.2)$ \\
Widower & $56(25.22)$ \\
Single & \\
Origin & $161(72.5)$ \\
Metropolitan Region of Recife & \\
Countryside & \\
\hline
\end{tabular}

Education (years)

$\leq 9$

$151(68.0)$

$>9$

$71(32.0)$

Monthly income (minimum wage)*

$\leq 1$

149 (67.1)

$>1$

Occupation

Retired / Pensioner

127 (57.2)

Homeworker

44 (19.8)

Wage earner

15 (6.8)

Autonomous

21 (9.5)

Others

15 (6.8)

*Monthly income based on the value of the minimum wage at the time of the study (R\$937.00) 
Table 2 - Characterization of personal history, family and drugs used in patients using oral anticoagulants $(\mathrm{n}=222)$

\begin{tabular}{lc}
\hline Variables & n (\%) \\
\hline Personal background* & \\
Systemic Hypertension & $202(91.0)$ \\
Sedentary lifestyle & $119(53.6)$ \\
Stress** & $86(38.7)$ \\
Dyslipidemia & $85(38.3)$ \\
Overweight and obesity & $50(22.5)$ \\
Diabetes mellitus & $40(18.0)$ \\
Alcoholism & $35(15.8)$ \\
Smoking & $15(6.8)$ \\
Kidney disease & $15(6.8)$ \\
Family history* & \\
Systemic hypertension & $157(70.7)$ \\
Other heart diseases & $133(59.9)$ \\
Diabetes mellitus & $112(50.5)$ \\
Stroke & $91(41.0)$ \\
Kidney disease & $24(10.8)$ \\
\hline Multiple responses; ** self-reported &
\end{tabular}

Table 3 shows that the main clinical indications for oral anticoagulation therapy were: atrial fibrillation $(50.4 \%)$ and valvular heart disease $(50.4 \%)$. Among those who had heart valve prosthesis, 17.5\% had mechanical prostheses and $26.5 \%$ biological ones. In reference to the control of the International Normalized Ratio, it was observed that on the day of the interview, 200 patients showed previous exam values, 22 were in the first outpatient evaluation, not presenting therefore previous values of the exam. Regarding the results above, $39.9 \%$ were within the therapeutic range. At the moment of outpatient consultation, in turn, $57.2 \%$ of the patients had no values within the recommended therapeutic range, requiring adjustment in the drug dose.

About the time of treatment, it was observed that most patients were on therapy for more than six months (65.8\%). It was also found that $64.9 \%$ of the patients were in treatment for less than six months, the average follow-up time was between 4.2 and 4.7 months, and it may vary from patient to patient in the first day of follow up even in those followed for over a year.

When one investigated the complications related to the treatment, $21.2 \%$ had bleeding episodes and $11.7 \%$ thromboembolic and the average length of stay required for the treatment of these events is $2.20 \pm 8.17$ days.

Table 3 - Clinical indications and data relating to outpatient treatment of patients using oral anticoagulants ( $\mathrm{n}=222)$

\begin{tabular}{|c|c|c|}
\hline Variables & n (\%) & $\mathbf{p}^{1}$ \\
\hline \multicolumn{3}{|l|}{ Clinical indication* } \\
\hline Atrial fibrillation & $112(50.4)$ & \\
\hline Valvular heart disease & $112(50.4)$ & \\
\hline $\begin{array}{l}\text { Pulmonary embolism and/or deep vein } \\
\text { thrombosis }\end{array}$ & $21(9.4)$ & \\
\hline \multicolumn{3}{|l|}{ Use of prosthetic valve } \\
\hline Mechanical prostheses & $39(17.5)$ & \\
\hline Bioprostheses & $59(26.5)$ & \\
\hline \multicolumn{3}{|c|}{ International Normalized Ratio Range - last evaluation } \\
\hline Below the indicated range & $75(33.8)$ & \multirow{4}{*}{$<0.001$} \\
\hline Normal** & $87(39.2)$ & \\
\hline Above the indicated range & $38(17.1)$ & \\
\hline First evaluation & $22(9.9)$ & \\
\hline \multicolumn{3}{|l|}{ Adjusted International Normalized Ratio Range } \\
\hline Below the indicated range & $81(36.5)$ & \multirow{4}{*}{$<0.001$} \\
\hline Normal $^{* *}$ & $95(42.8)$ & \\
\hline Above the range indicated by & $46(20.7)$ & \\
\hline $\begin{array}{l}\text { International Normalized Ratio with appro- } \\
\text { priate adjustment }\end{array}$ & $95(42.8)$ & \\
\hline \multicolumn{3}{|l|}{ Treatment time (anticoagulant) (months) } \\
\hline$\leq 6$ & $76(34.2)$ & \multirow{2}{*}{$<0.001$} \\
\hline$>6$ & $146(65.8)$ & \\
\hline \multicolumn{3}{|l|}{ Outpatient follow-up time (months) } \\
\hline$\leq 6$ & $144(64.9)$ & \multirow{2}{*}{$<0.001$} \\
\hline$>6$ & $78(35.1)$ & \\
\hline \multicolumn{3}{|l|}{ Complications during treatment } \\
\hline Hemorrhagic & $47(21.2)$ & \\
\hline Thromboembolic & $26(11.7)$ & \\
\hline
\end{tabular}




\section{Discussion}

The study provided important information about aspects that reflect the complexity of the treatment with oral anticoagulants. However, it has limitations because it does not show the magnitude of the problem, since the results cannot be generalized, but it should be analyzed in an attempt to support assistance actions during health care.

Treatment with oral anticoagulants has increased significantly in recent years. The difficulties in maintaining adequate and stable treatment have mobilized health professionals to seek care that minimizes risks related to medication and develop studies aimed at knowing the profile of the subjects and main aspects of treatment ${ }^{(6)}$.

The profile of the patients attended at the clinic of this study showed a predominance of females, corroborating the findings of other studies ${ }^{(4,7-8)}$. In contrast, another study brings males in higher percentages using oral anticoagulants ${ }^{(9)}$.

Regarding age, the age distribution was less than 60 years old, corroborating studies in developing countries with similar average age $\mathrm{e}^{(4,7)}$. Despite the variation in average age among the surveys, there is consensus among a significant proportion of older people who make use of oral anticoagulants, which can be explained by the fact that this age group have comorbidities that are indicated for therapy with oral anticoagulants $^{(4)}$.

Regarding marital status, the results presented a majority of married and/or civil union, confirming another study with the same population ${ }^{(4)}$. During data collection, it was found that many patients attended the consultations accompanied by spouses, mentioning their help with the therapy and attention with the guidelines provided by health professionals. So, to sum up, it is emphasized that family support for these patients becomes an important ally for treatment with oral anticoagulants.

Regarding race/ethnicity, the majority of the people declared themselves as brown. National and international studies corroborate these results when they demonstrate the predominance of white participants $^{(4,10)}$. However, considering the large racial miscegenation existing in Brazil and the regional characteristics of the population, it is difficult to measure accurately the influence of this variable on the treatment with oral anticoagulants.

Regarding the origin, the majority of respondents were from the metropolitan region of Recife, Pernambuco, Brazil, and those from the countryside of the state, needed to commute to the referred institution for outpatient treatment. It is possible, in this case, to rethink the health situation that these people are subjected to, bringing reflections on the possible and real reasons that lead patients to move from their place of origin to be treated on an outpatient basis in the capital, whereas the dose adjustment of oral anticoagulants can be performed by a non-specialist medical professional in primary health care.

Still analyzing the socio-demographic data, most of the participants had low education, also prevalent results in other studies conducted in public services that attend patients using oral anticoagulant $t^{(4,8)}$. In terms of occupation, most did not exercise professional activities, which may be explained by the predominance of retired people and pensioners, as well as due to unemployment, or to the lack of physical work opportunities or limitations imposed by the disease.

Regarding comorbidities, hypertension presented a big highlight. So it is highlighted the prevalence of sedentary lifestyle and everyday stress (self-reported), as risk factors for cardiovascular diseases. The comorbidities including atrial fibrillation, represent major risk factor for the occurrence of other cardiovascular diseases such as cerebrovascular accident ${ }^{(10)}$.

In regard to the drugs most commonly used, one observed a frequent of use of statins and antibiotics. In a study on the pharmacological profile and drug interactions with antidepressants, the drugs most frequently reported included simvastatin and 
ciprofloxacin. It should be added that the indication of the use of anticoagulants, along with other medications, increased as a result of age, due to the aging process that causes comorbidities ${ }^{(11)}$.

Among the indications for oral anticoagulation therapy, heart valve diseases and atrial fibrillation were equally frequent, being used both for primary treatment condition and associated in the same individual. These findings support studies that demonstrate the high prevalence of these diseases and the need to optimize the treatment with oral anticoagulants, in order to reduce significantly the number of thromboembolic and hemorrhagic complications related to the therapy ${ }^{(12-13)}$.

Atrial fibrillation is a cardiac rhythm disorder that is associated with blood stasis within the atria with a greater predisposition to the formation of thrombi that may embolize systematically and reach the brain. Studies show that patients with atrial fibrillation are at increased risk, five times higher, of having a stroke ${ }^{(13-14)}$. Concerning valvular heart diseases, valve replacement with mechanical or biological prosthesis increases considerably the risk of thromboembolic events due to the thrombogenic characteristics of the prosthesis. This fact creates the need for the use of prophylactic anticoagulant agents that generally increase the risk of thromboembolism in the early therapy, decreasing gradually as the prosthesis is endothelial ${ }^{(15)}$.

In this study, it was observed that most participants needed to adjust the dose due to the target value of the International Normalized Ratio for the condition. This finding shows the high risk of complications related to the proposed treatment, for example bleeding complications, or values above the therapeutic range, or thromboembolic complications, when values below the reference are present.

With regard to the duration of use of oral anticoagulants, it was observed that most participants were in treatment for more than six months, whi- ch may be related to a better acceptance of therapy and perception of health-related improvements ${ }^{(4)}$. At the time of the interview, $64.9 \%$ of participants were being followed by less than six months, emphasizing the importance of valuing this moment, in order to encourage the effective participation of patients in the treatment.

From the development of this study, it was possible to identify relevant features and aspects to be highlighted at the time of care and health care of patients using oral anticoagulation therapy. Studies that characterize individuals and discuss aspects that can affect the quality and effectiveness of treatment are of great importance as they provide subsidies for the health care team, assisting in health care planning. Moreover, they are able to guide new studies related to the treatment with anticoagulants.

\section{Conclusion}

It was evident a predominantly female group, with low socioeconomic status, associated comorbidities and prolonged time of treatment with oral anticoagulants. It constitutes a greater part of a vulnerable group whose characteristics can affect the quality of the treatment, and characteristics related to the particular culture of northeastern Brazil, not found in outpatient units of anticoagulation in other regions of the country.

\section{Collaborations}

Figueirêdo TR and Bezerra SMMS contributed with the conception and the design, analysis and interpretation of data and writing of the article. Araújo HVS, Silva T, Costa CRB and Silveira MMBM contributed with the writing of the article and relevant critical review of the intellectual content. All the authors contributed with the final approval of the version to be published. 


\section{References}

1. Spring B, Ockene JK, Gidding SS, Mozaffarian D, Moore S, Rosal MC, et al. Better population health through behavior change in adults a call to action. Circulation. 2013; 128(9):2169-76. doi: https:// doi.org/10.1161/01.cir.0000435173.25936.e1

2. World Health Organization Report. Global status report on noncommunicable diseases 2014 [Internet]. 2014 [cited 2017 Mar. 20]. Available from: http://apps.who.int/iris/ bitstream/10665/148114/1/9789241564854_ eng.pdf?ua=1

3. Pelegrino FM, Dantas RAS, Corbi ISA, Carvalho ARS, Schmidt A, Pazin Filho A. Cross-Cultural adaptation and psychometric properties of the brazilian-portuguese version of the duke anticoagulation satisfaction scale. J Clin Nurs. 2012; 21(17-18):2509-17. doi: http://dx.doi. org/10.1111/j.1365-2702.2011.03869.x

4. Carvalho ARS, Ciol MA, Tiu F, Rossi LA, Dantas RAS. Oral anticoagulation: the impact of the therapy in health-related quality of life at sixmonth follow-up. Rev Latino-Am Enfermagem. 2013; 21(Spec):105-12. doi: http://dx.doi. org/10.1590/S0104-11692013000700014

5. Pelegrino FM, Bolela F, Corbi ISA, Carvalho ARS, Dantas RAS. Educational protocol for patients on oral anticoagulant therapy: construction and validation. Texto Contexto Enferm. 2014; 23(3):799-806. doi: http://dx.doi. org/10.1590/0104-07072014001440013

6. Simonetti SH, Faro ACM, Bianchi ERF. Adherence to therapy with oral anticoagulants: an integrative review. Rev Enferm UFPE on line [Internet]. 2014 [cited 2017 Mar. 16]; 8(8):2854-63. Available from: http://www.revista.ufpe.br/revistaenfermagem/ index.php/revista/article/view/6479/pdf_5959

7. Ferreira F, Antunes E, Neves RC, Farias F, Malveiro P, Chon H, et al. Telemonitorização de INR: Eficácia e Segurança de um Sistema de Avaliação em 453 doentes. Acta Med Port [Internet]. 2012 [citado 2017 mar. 12]; 25(5):297-300. Disponível em: http://www.actamedicaportuguesa.com/revista/ index.php/amp/article/view/288/83

8. Chenot JF, Hua TD, Abed MA, Schneider-Rudt $\mathrm{H}$, Fried T, Schneider S, et al. Safety relevant knowledge of orally anticoagulated patients without self-monitoring: a baseline survey in primary care. BMC Fam Prac. 2014; 15:104. doi: https://doi.org/10.1186/1471-2296-15-104
9. Kitahara ST, Silva EA, Fagundes DJ, Costa LMA, Ferraz RF, Costa FAA. Avaliação da Variação de Razão Normalizada Internacional em Pacientes Anticoagulados através de Metodologia Diferenciada. Rev Bras Cardiol [Internet]. 2014 [citado 2017 mar. 12]; 27(5):342-34. Disponível em:http:// www.rbconline.org.br/artigo/avaliacao-da-variacao-de-razao-normalizada-internacional-em-pacientes-anticoagulados-atraves-de-metodologia-diferenciada/

10. Stambler B, Scazzuso F. Targenting stroke risk and improving outcomes in patients with atrial fibrillation in Latin America. São Paulo Med J. 2016; 134(6):534-42. doi: http://dx.doi. org/10.1590/1516-3180.2015.0222110716

11. Teles JS, Fukuda EY, Fedor D. Warfarin: pharmacological profile and drug interactions with antidepressants. Einstein. 2012; 10(1):1105. doi: http://dx.doi.org/10.1590/S167945082012000100024

12. Almeida Neto OP, Cunha CM, Rodrigues CM, Resende TC. Perfil clínico, adesão e satisfação terapêutica de pacientes em uso de anticoagulantes orais. Rev Aten Saúde. 2016; 14(47):61-6. doi: http://dx.doi.org/10.13037/ras.vol14n47.3389

13. Ferreira J, Mirco A. Systematic review of costeffectiveness analyses of novel oral anticoagulants for stroke prevention in atrial fibrillation. Rev Port Cardiol. 2015; 34(3):179-91. doi: http://dx.doi. org/10.1016/j.repc.2014.08.008

14. Fernandes ALC, Andrade AMS, Cruz CMS, Oliveira EN. Novos anticoagulantes orais (NOACs) na prevenção de acidente vascular encefálico (AVE) e fenômenos tromboembólicos em pacientes com fibrilação atrial. Rev Soc Bras Clin Med [Internet]. 2015 [citado 23 jun. 2017]; 13(2):98-106. Disponível em: http://files.bvs.br/ upload/S/1679-1010/2015/v13n2/a4736.pdf

15. Lorga Filho Am, Azmus AD, Saeiro AM, Quadros AS, Avezum Junior A, Marques AC, et al. Brazilian guidelines on antiplatelet and anticoagulant agents in cardiology. Arq Bras Cardiol. 2013; 101(3supl3):1-93. doi: http://dx.doi. org/10.5935/abc.2013S009 